\title{
A retrospective study of urinary tract infections in post-operative gynae- oncology patients in a tertiary care hospital of Chhattisgarh
}

\author{
Jindal $\mathbf{M}^{\mathbf{1}}$, Ratnani $\mathbf{R}^{\mathbf{2}}$ \\ ${ }^{1}$ Dr. Monika Jindal, Assistant Professor, ${ }^{2}$ Prof. Rekha Ratnani, Professor and Head, Department of Obstetrics and \\ Gynaecology, Chandulal Chandrakar Memorial Medical College, Durg, Chhattisgarh, India. \\ Corresponding Author: Dr. Monika Jindal, Assistant Professor, Department of Obstetrics and Gynaecology, Chandulal \\ Chandrakar Memorial Medical College, Durg, Chhattisgarh, India, Email: drmonickajindal@gmail.com
}

\begin{abstract}
Introduction: Urinary tract infections (UTIs) are second most common hospital acquired infections. There are multiple risk factors for UTIs. Patients with gynecological malignancies undergoing treatment are more predisposed for getting UTIs as they have multiple risk factors including prolong duration of urinary catheterization. Objective: This retrospective study was done to find the incidence and risk factors related to the occurrence of urinary tract infections (UTIs) inpost-surgerygy necological cancer patients. Methods: Data of Ninety two women was collected and reviewed with domains covering known risk factors for the occurrence of urinary tract infections. Bacteriuria was defined as $>10^{5}$ colony-forming units per milliliter. Results: $38 \%$ of women had UTI post-operatively. Among them, 71.4\% infections were Escherichia coli. Catheter in situ for 7 days duration was found to be highly significant in the occurrence of UTI $(p<0.01$; OR 2.62). A positive correlation was found between the duration of the catheter in situ and type of UTI $(\mathrm{P}<0.01)$. Conclusions: Urinary catheterization is known to be related to hospital-acquired infection, and risk can be reduced by a shorter duration of catheterization post surgery. Gynecologists need to be more aware of this risk and identify women who are more likely to be catheterized for longer and use preventive strategies for managing infection, such as silver nitrite-lined catheters.
\end{abstract}

Keywords- Gynecological cancer, Urinary tract infections, Bacteriuria, Catheter in situ

\section{Introduction}

Hospital-acquired infections (HAI) are defined as 'infections acquired in hospital likely to complicate illness, cause anxiety and discomfort and can lead to death'[1]. Urinary tract infections (UTIs) are among the most common HAIs [2]. UTIs (19.7\%) are second only to gastrointestinal infections of total HAIs. Nosocomial infections increases the morbidity and mortality, hence their prevention should be a priority for healthcare professionals.Urinary tract infections, severity of underlying disease, increased age, duration of catheterrization and type of hospital service (medicine/ general surgery) have been found to be significantly correlated with increased morbidity and mortality in patients [3].

Existing literature suggests various risk factors for UTI like a past history of UTIs, urinary tract anomalies, history of diabetes mellitus, post-menopausal, frequent sexual intercourse, renal problems, and bladder problems [4]. Patients treated for gynecological cancers often have these characteristics and often have an indwelling urinary

Manuscript received: $10^{\text {th }}$ February 2018

Reviewed: $20^{\text {th }}$ February 2018

Author Corrected: $26^{\text {th }}$ February 2018

Accepted for Publication: $1^{\text {st }}$ March 2018

Obsgyne Review: Journal of Obstetrics and Gynecology catheter for a long duration. Urinary catheterization is an unavoidable part of any gynaeoncology surgery as it aids post-operative voiding dysfunction caused by 'anaesthesia, analgesia and immobility'. Early identification and treatment of any infections will result in the best outcome from these potentially serious complications. Nonetheless, the majority of papers published on the subject of urinary tract disorders including inflammation are on patients with cancers of the uterine cervix and few authors give any special value to UTI as a post therapeutic complication on malignant neoplasms of the reproductive system in women.

Identifying risk factors, correct etiological diagnosis and appropriate treatment can have the effect of reducing the numbers of nosocomial infections. The objective of this study was to determine risk factors for women with gynecological cancers who have undergone surgery in relation to UTI occurrence. An understanding of the risk factors for UTI in this population can improve risk assessment and will improve practice and patient outcome. There is lack of data from developing world and hence the need of this study.

Available online at: www.medresearch.in 6 | P a g e 


\section{Methods}

Type of Study: Retrospective Cohort Study

Place: Chandulal Chandrakar Memorial Hospital, Durg, Chhattisgarh.

Inclusion Criteria: All women with gynaecological malignancies who underwent surgery in Chandulal Chandrakar Memorial Medical College, Durg between January 2014 to December 2017.

Sampling Methods: A review of medical records of 92 women with gynaecological cancers was evaluated to determine the risk factors for the development of UTIs. We also sought to develop a risk assessment tool to enable the rapid identification of high-risk individuals. Data was retrospectively evaluated of 92 women who had undergone gynaecological surgery for cancer in the years 2014 to 2017. A detailed proforma was used for the retrospective medical record review and included patient details, risk factors and the most common UTIs identified in the literature review. The UTI was defined as a midstream sample or a catheter specimen sample of urine

\section{Original Research Article}

having a bacterial count of $>10^{5} \mathrm{cfu} / \mathrm{mL}$. A patient's urine sample was considered significant only when it was accompanied by presence of $>5$ pus cells/hpf or was associated with signs or symptoms of an infection, for example, burning micturition, pyrexia and/ or abdominal pain.

Exclusion Criteria: All records which contained incomplete information were excluded. However, we did not find any records which were incomplete and hence all patients were enrolled.

Statistical Methods: The relationship between categorical variables and the significance of this relationship were analysed using cross tabulations against the incidence of UTI. Pearson's chi-squared test $\left(\mathrm{X}^{2}\right)$, Cramer's V, MannWhitney U (MWU) and bivariate correlations, for example Kendall's tau (t), were undertaken, as appropriate, to determine the significance of the findings. Data were analyzed using SPSS v15 (SPSS Inc., Chicago, IL, USA; 2006).

\section{Results}

The median age of the women in the sample was 56 years (13-68 years). Seventy Nine per cent women were postmenopausal and the ratio of pre-menopausal to post-menopausal clients was 1:4 (21.7\% vs. $78.3 \%) .39 .1 \%$ of the population $(\mathrm{n}=36) \mathrm{had}$ ovarian cancer, $35.9 \%(n=33)$ had cervical cancer, $22.8 \%(n=21)$ had endometrial cancer and $2.2 \%(n=2)$ had vulval cancer (Fig. 1).

Rates and types of infection- A total of $38 \%(\mathrm{n}=35)$ of the women had a postoperative UTI. E.coli $(71.4 \%, \mathrm{n}=25)$ was the commonest UTI followed by Candida $(5.7 \%, \mathrm{n}=2)$, Coliforms $(5.7 \%, \mathrm{n}=2)$, Proteus $(5.7 \%, \mathrm{n}=2)$, Pseudomonas aeruginosa $(5.7 \%, \mathrm{n}=2)$, Citrobacter freundii $(2.9 \%, \mathrm{n}=1)$, and Enterobacter spp. $(2.9 \%, \mathrm{n}=1)$. Some women developed polymicrobial infection. The median age of women developing postoperative UTI was 47 years. Thirty seven per cent $(\mathrm{n}=$ 13) had ovarian cancer, $28.6 \%(\mathrm{n}=10)$ had endometrial cancer, $28.6 \%(\mathrm{n}=10)$ had cervical cancer and $5.7(\mathrm{n}=2)$ had vulval cancer. Seventy-one per cent $(n=25)$ were post-menopausal and $28.6 \%(n=10)$ were pre-menopausal women (Table 1$)$.

Contributory factors to the occurrence of urinary tract infections- Factors like age, type of cancer, menopausal status, history of diabetes, combined history of UTI, renal disease, uterine prolapse and urinary abnormalities, body mass index and the presence of a UTI pre-operatively were explored in the analysis. Although identified in the literature as possible risk factors, these were not found to be significant risk factors for the formation of a post-operative UTI in our study. There was a greater proportion of post-menopausal women to pre-menopausal women in the sample ( $\mathrm{n}=72$ vs. $n=20)$. Subsequently, $71 \%$ of post-operative UTIs were found in the post-menopausal group. Small numbers in each subgroup prevented us to find any statistical correlation between the type ofuropathogen and menopausal status.

A small percentage of the women had a history of diabetes $(6.5 \%)$ and only $16.7 \%$ of these women were diagnosed (positive urine culture) with a UTI post-operatively. Although data were combined for history of UTI, renal disease, uterine prolapse and urinary abnormalities, only $5.5 \%$ of the population had one or all of these co-morbidities. Only two women had a catheter in situ pre-operatively and $3.3 \%$ of the population had a UTI pre-operatively and post-operatively. The duration of catheterization was found to be the most significant factor in relation to UTI incidence. Having a catheter in situ for $>7$ days was found to be highly significant $\left(\mathrm{X}^{2}(1)=4.602, \mathrm{P}<0.01\right)$, with an odds ratio of 2.62 . The presence of a catheter for $0-3$ days increased the risk of UTI formation as compared to $4-6$ days $[\mathrm{U}=2988, \mathrm{P}<0.05$ (mean ranks 109.97 vs. 85.09)]. The duration of catheterization was positively correlated with the type of uropathogen $(\mathrm{t}=.221, \mathrm{P}<0.01)$. E. coli accounted for $18.5 \%$ of UTIs for days $0-3,27.3 \%$ for days $4-6$ and $37.4 \%$ for the 7 -day group (Table 1 ). 
Original Research Article

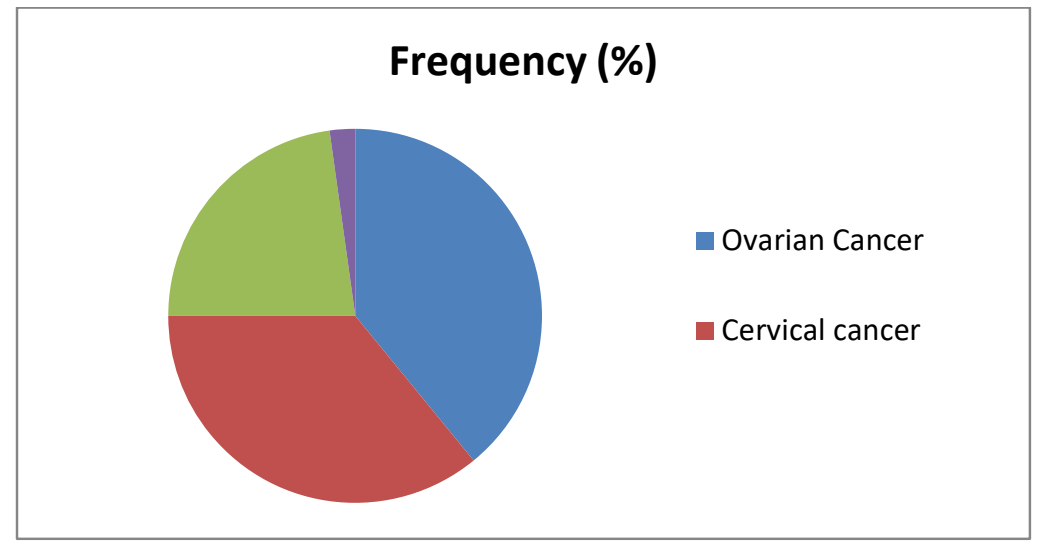

Figure-1: Graph showing types of cancers and their frequency in the study population

Table-1: Population in terms of risk factors.

\begin{tabular}{|c|c|}
\hline Parameter & $\begin{array}{c}\text { Frequency n }(\%) \\
n=92(100)\end{array}$ \\
\hline Median Age (Range) & $56(13-68)$ \\
\hline \multicolumn{2}{|l|}{ Body Mass Index (BMI) } \\
\hline $\mathrm{BMI}<18.5$ & $(3.5 \%)$ \\
\hline $\mathrm{BMI}=18.5-25$ & $(31 \%)$ \\
\hline $\mathrm{BMI}=25-30$ & $(33.5 \%)$ \\
\hline $\mathrm{BMI}>30$ & $(32 \%)$ \\
\hline \multicolumn{2}{|l|}{ Cancer } \\
\hline Cervix & $33(35.9 \%)$ \\
\hline Endometrium & $21(22.8 \%)$ \\
\hline Ovary & $36(39.1 \%)$ \\
\hline Vulva & $2(2.2 \%)$ \\
\hline \multicolumn{2}{|l|}{ Menopausal Status } \\
\hline Pre-menopausal women & $20(21.7 \%)$ \\
\hline Post-Menopausal Women & $72(78.3 \%)$ \\
\hline History of Diabetes & $6(6.5 \%)$ \\
\hline History of UTIs & $15(16.7 \%)$ \\
\hline History of Co-morbidities & $5(5.5 \%)$ \\
\hline Uterine Prolapse & $5(5.5 \%)$ \\
\hline \multicolumn{2}{|l|}{ Catheter } \\
\hline Preoperatively & $2(2.2 \%)$ \\
\hline Intraoperatively & $90(97.8 \%)$ \\
\hline Postoperatively & $90(97.8 \%)$ \\
\hline Catheter in situ. $>7$ days & $18(19.7 \%)$ \\
\hline
\end{tabular}

*History of co-morbidities include renal disease, bladder cancer, bowel cancer, breast cancer, ovarian cancer, cerebrovascular accident, urinary tract abnormalities.

\section{Discussion}

Thirty-eight per cent (38\%) of women had post-operative UTI, reconfirming that UTI is a common complication post gynaeoncosurgeries. However this rate was double than the Third Prevalence Survey for HCAIs conducted in acute hospitals in 2006 (19.7\%). This difference could be due to difference of postoperative care in the western world and the third world countries.In our study, E.coli accounted for $71.4 \%$ of UTI and was the commonest infection. Our findings were synonymous with other studies $[5,6]$. Their findings are also quite similar to our findings for other uropathogens as well where Candida, Coliform, Proteus and pseudomonas each accounted for 5.7\%, Citrobacter freundii and Enterobacter spp. each for $2.9 \%$. 
Original Research Article

Uroepithelial cells can be normally colonized by Escherichia spp., Klebsiella spp., Proteus spp., Corynebacterium spp., Staphylococcus spp. and Candida spp. However, pathogenic infection can occur as a result of decreased immunity which may occur in cancer patients as a result of the disease or treatment. Peri-operative stress can also result in immuno-suppression and increased risk of postoperative infection. The synergistic effect of co-occurring symptoms may affect patient outcomes, for example a reduction, delay or discontinuation of treatment [7]. This can add additional symptoms and discomfort at a time of anxiety for such women.

The most important and significant risk factor for post-operative UTI in the sample population was duration of catheterization. Our study found that an individual was 2.62 times more likely to develop a UTI postoperatively if they were catheterized for $>7$ days, which is in concurrence with literature [8]. Catheterization up to 3 days was not a risk factor in the formation of a UTI. Our study found that $23 \%$ of catheterizations from 0 to 3 days resulted in a post-operative UTI (p<0.05). Our study was in contrast to the findings of Wald et al [9] who found that patients catheterized for 2 days or more had double the likelihood of developing a UTI than those catheterized for 2 days or less.

Table 2: Urinary tract infection (UTI) risk assessment tool [15 The UTI risk assessment tool lists the factors highlighted in previous research and in this study that may contribute to the development of a UTI. Risk categories and interventions have been proposed. However, this tool would need testing in practice to determine its potential for risk reduction.

\begin{tabular}{|c|c|c|c|c|c|c|}
\hline \multicolumn{3}{|c|}{ Risk factors } & Score & Date & Date & Date \\
\hline \multicolumn{7}{|c|}{ Menopausal Status } \\
\hline \multicolumn{3}{|c|}{ Pre-menopausal } & 0 & & & \\
\hline \multicolumn{3}{|c|}{ Postmenopausal } & 1 & & & \\
\hline \multicolumn{7}{|c|}{ Co-Morbidities } \\
\hline \multicolumn{3}{|c|}{ History of UTI } & 1 & & & \\
\hline \multicolumn{3}{|c|}{ History of Diabetes } & 1 & & & \\
\hline \multicolumn{3}{|c|}{ History of Urinary tract anomalies } & 1 & & & \\
\hline \multicolumn{3}{|c|}{ History of Renal Disease } & 1 & & & \\
\hline \multicolumn{7}{|c|}{ Continence } \\
\hline \multicolumn{3}{|c|}{ Urinary Incontinence } & 1 & & & \\
\hline \multicolumn{3}{|c|}{ Fecal Incontinence } & 2 & & & \\
\hline \multicolumn{3}{|c|}{ Urinary and fecal Incontinence } & 3 & & & \\
\hline \multicolumn{7}{|c|}{ Activities of Daily living } \\
\hline \multicolumn{3}{|c|}{ Self caring } & 1 & & & \\
\hline \multicolumn{3}{|c|}{ Not Self caring } & 2 & & & \\
\hline \multicolumn{7}{|c|}{ Body Mass index (BMI) } \\
\hline \multicolumn{3}{|c|}{$<30$} & 1 & & & \\
\hline \multicolumn{3}{|c|}{$>30$} & 2 & & & \\
\hline \multicolumn{7}{|c|}{ Chemotherapy/Radiotherapy Pre-operatively } \\
\hline \multicolumn{3}{|c|}{ No } & 0 & & & \\
\hline \multicolumn{3}{|c|}{ Yes } & 1 & & & \\
\hline \multicolumn{7}{|c|}{ Estimated Duration of Catheter in Situ } \\
\hline \multicolumn{3}{|c|}{$<3$ days } & 1 & & & \\
\hline \multicolumn{3}{|c|}{ 4-6 days } & 2 & & & \\
\hline \multicolumn{3}{|c|}{$>7$ days } & 3 & & & \\
\hline Levels of Risk & Cut-offs & & & rventic & & \\
\hline Low Risk & $2-4$ & Good pe & $\begin{array}{l}\text { ene, goc } \\
\text { ntake ( }\end{array}$ & $\begin{array}{l}\text { er hygi } \\
\text { as per } n\end{array}$ & $\begin{array}{l}\text { es, clos } \\
\text { tructio }\end{array}$ & n), good \\
\hline Medium Risk & $5-8$ & Regu & is nitrit & $\mathrm{k}+$ giv & s for lc & roup \\
\hline High Risk & $>9$ & & ite cath & ve advi & ow-risl & \\
\hline
\end{tabular}

Our study has some limitations. This was a retrospective single center study with a small sample size which was relatively small sample for a risk analysis. 
Original Research Article

Approximately $80 \%$ of nosocomial UTIs are due to indwelling catheters [10]. For each day catheterized, the risk of developing bacteriuria can increase by $5 \%$ [11,12]. Our findings also support the concept of accumulating risk of infection which is caused by catheterization. Reducing the number of days that women are catheterized could drastically reduce infection. However, reducing the use of urinary catheters is not easy in practice. Our findings from this study in light of previous research, removal of catheters at day 2 would be advantageous taking into account the patient's 'wellness' at the time of decision making. The use of the silver alloy catheters in high risk group may help in reducing the subsequent risk of UTI. Silver, being a nontoxic prominent broad-spectrum antimicrobial, has been shown to be effective against urinary infective agents, such as E. coli $[13,14]$. Their relative lack of use is due to their higher costs. Health education can also help in reducing the risk. National infection control guidelines emphasize the importance of personal hygiene, catheter care and health education.

Risk assessment is important in reducing infection and in planning future care. Taking into account the risk factors identified in our study and the risk factors already highlighted, a UTI risk assessment tool has been formulated (Table: 2).

\section{Conclusions}

Our study confirms that increased duration of catheterrization is animportant risk factor contributing to the incidence of UTI andis synonymous with the findings of other studies. It has also highlighted the significance of the elevated risk caused by catheterization for 7 days or more, to the gynecological cancer patient group. The use of silver alloy catheters in high risk group may help in subsequent reduction of risk of UTI. E.coli still remains the most common cause of UTI. Use of UTI risk assessment tool may help in reducing infection and planning further care. However, this tool needs validation in future studies.

What this Study Adds? - Use of UTI risk assessment tool may predict UTI, but this needs further validation in larger prospective studies.

Author Contributions: Monika Jindal collected, compiled and analyzed the data and wrote the manuscript. Rekha Ratnani gave intellectual inputs in editing the manuscript and the study was carried out under her supervision.

\section{Funding: Nil, Conflict of interest: Nil Permission from IRB: Yes}

\section{References}

1. The Health Protection Agency (2009) Healthcare Associated Infections (HCAI). Available at: http://www. hpa. org.uk/web w/HPAweb \& Page \& HPA web Auto ListNa me/Page/1191942126522.

2. Smyth ET, McIlvenny G, Enstone JE, Emmerson AM, Humphreys H, Fitzpatrick F, Davies E, Newcombe RG, Spencer RC; Hospital Infection Society Prevalence Survey Steering Group. Four country health care associated infection prevalence survey 2006: overview of the results. J Hosp Infect. 2008 Jul;69(3):230-48. doi: 10. 1016/j.jhin.2008.04.020. Epub 2008 Jun 11.
3. Saint S. Clinical and economic consequences of nosocomial catheter-related bacteriuria. Am J Infect Control. 2000 Feb; 28 (1):68-75.

4. Sheffield JS, Cunningham FG. Urinary tract infection in women. Obstet Gynecol. 2005 Nov; 106 (5 Pt 1): 1085-92.

5. Wazait HD, Patel HR, Veer V, Kelsey M, Van Der Meulen JH, Miller RA, Emberton M. Catheter-associated urinary tract infections: prevalence of uropathogens and pattern of antimicrobial resistance in a UK hospital (19962001). BJU Int. 2003 Jun;91(9):806-9.

6. Kucheria R, Dasgupta P, Sacks SH, Khan MS, Sheerin NS. Urinary tract infections: new insights into a common problem. Postgrad Med J. 2005 Feb; 81 (952):83-6.

7. Dodd MJ, Miaskowski C, Lee KA. Occurrence of symptom clusters. J Natl Cancer Inst Monogr. 2004; (32): 76-8.

8. Shapiro M, Simchen E, Izraeli S, Sacks TG. A multivariate analysis of risk factors for acquiring bacteriuria in patients with indwelling urinary catheters for longer than 24 hours. Infect Control. 1984 Nov; 5 (11): 525-32.

9. Wald HL, Ma A, Bratzler DW, Kramer AM. Indwelling urinary catheter use in the postoperative period: analysis of the national surgical infection prevention project data. Arch Surg. 2008 Jun;143(6):551-7. doi: 10.1001/archsurg. 143.6.551.

10. Plowman R, Graves N, Esquivel J, Roberts JA. An economic model to assess the cost and benefits of the routine use of silver alloy coated urinary catheters to reduce the risk of urinary tract infections in catheterized patients. J Hosp Infect. 2001 May;48(1):33-42. 


\section{Original Research Article}

11. Garibaldi RA,BurkeJP,DickmanML,SmithCB. Factors predisposing to bacteriuria during indwelling urethral catheterization.N Engl J Med. 1974 Aug 1;291 (5): 215-9.

12. Schaeffer AJ. Catheter associated bacteriuria. The Urologic Clinics of North America 1986; 13(4): 735-47.

13. Sondi I, Salopek-SondiB.Silver nanoparticles as antimicrobial agent: a case study on E. coli as a model for Gram-negative bacteria. J Colloid Interface Sci. 2004 Jul $1 ; 275(1): 177-82$.
14. Davenport K, Keeley FX. Evidence for the use of silver-alloy-coated urethral catheters. J Hosp Infect. 2005 Aug; 60 (4):298-303.

15. Crosby-Nwaobi RR, Faithfull S. High risk of urinary tract infections in post-operative gynaecology patients: a retrospective case analysis. Eur J Cancer Care (Engl). 2011 Nov; 20 (6): 825-31. doi: 10. 1111/j. 1365-2354. 2011. 01283.x.Epub 2011 Aug 24.

\section{How to cite this article?}

Jindal M, Ratnani R. A retrospective study of urinary tract infections in post-operative gynae-oncology patients in a tertiary care hospital of Chhattisgarh. Obs Rev:J obstet Gynecol 2018;4(1):6-11.doi: 10.17511/joog.2018.i01.02. 